\section{A danger to science?}

James E. Lovelock

The Rebirth of Nature. By Rupert Sheldrake. Century: 1990. Pp. 215. £14.99.

If Rupert Sheldrake had been a cosmologist, it would have been much easier to review his book; speculations about the universe range free and are judged by their entertainment value as well as by their scientific validity and use. But he is a biologist and at the present stage of perception biology seems vastly more complex than physics. My task is made difficult by more than just the complexity; the subject of the book falls within the discipline of evolutionary biology, a science that has long been in adversarial contest with religious fundamentalists over creation. Some evolutionary biollogists have evolved to become like their opponents, dogmatic authoritarians, knowing and teaching the absolute truth; almost as if they were the Sunday School superintendents of a fundamentalist sect; wonderfully expert at sniffing our evil. Some of these zealots have already categorized my own work as dangerous and, aware of their influence, I felt uneasy when writing this review. This new inquisition will surely use anything favourable I say about someone they regard as a real heretic as evidence of my own delinquency.

Perhaps Lewis Wolpert was right to say "Sheldrake's ideas are just nonsense", but for others to call them dangerous, or a threat to science, goes too far. The theory of formative causation makes testable predictions, although nothing has yet been reported that would divert the mainstream of science. Even if it is nonsense, errors, in the golden days of science, were well regarded. As Vilfredo Pareto said of Kepler, we should "prize the fruitful error, full of seeds bursting with their own corrections." Recognizing this need for fruitful errors, I do not regard the book as dangerous. Ideas like morphogenetic fields or morphic resonance may not even be good guesses, but burning might give them that piquant smoked flavour of martyrdom. Entertaining and informative though it is, I do not think this book yet merits such an accolade. The question is, are the errors fruitful?

I think so, if only because they identify the real danger to science: the acceptance of a censorship of ideas and the isolation of science in a naive mechanical reductionism. In certain ways the scientific

establishment has grown to resemble Eastern Europe of a few years ago. Deviations from the materialistic creed are pilloried as threats to science, whereas patent nonsense, like cold fusion, is swallowed whole. Science is not threatened by the imaginative ideas of the Sheldrakes of the world, but by those who would censor them. Sheldrake is a threat, but only to the established positions of those

\section{IMAGE
UNAVAILABLE
OR COPYRIGHT \\ IMAGE
UNAVAILABLE
FOR COPYRIGHT \\ IMAGE
UNAVAILABLE
FOR COPYRIGHT REASONS}

who teach and practice an authoritarian science. A healthy scientific community would accept or reject formative causation as the evidence appeared.

Some of us start a life of science motivated by a sense of wonder, but most now see science as an established career with the rewards of tenure and recognition for those who obey its inflexible rules. As a consequence, imagination is so disabled that naively we compare the exquisite complexity of living organisms, and their properties like intelligence, with the crudity of our trendy contraptions. Descartes, his disciples, and even opponents like Paley, thought of clockwork; steam engines with their control systems came later. I recall when the brain was compared to a telephone exchange, now of course it is said to be like a computer. What will it resemble next? This progression, where complex living entities that we do not understand are compared with the latest technological masterpiece, is human but absurd. Sheldrake is right to condemn

these uninspired mechanistic attempts to explain everything.

I believe that nature is objective and give thanks that we may never understand it. I know, from experience as an instrument designer and from trying to explain Gaia, that most scientists are blind to the circular logic of control theory. Even physiologists and systems engineers do not seem to realize that their view of organisms involves more than the simple reductionism of mainstream science, yet still is wholly objective. Understanding requires the top down view as much as the bottom up. The New Age antiscience that masquerades as holism is appealing because the lay public can sense the inadequacy of oversimplified reduction $\Xi$ and are insulted by ingenuous attempts to blind them with science.

This is why Sheldrake's notions are popular with the Greens. Policy makers and scientists who need to understand the philosophy and motivations of the Greens would do well to read the book, which is a new window into biology; it covers topics not ordinarily discussed, like life and organisms. Generations of scientists have grown up unaware of a past that included fierce debates over vitalism and animism. These were as much a part of scientific history as was the phlogiston theory in physics. The book is partisan, but well written and rich in good quotations; it faithfully retreads the crooked path of the history of biology and of the metaphor of Mother Nature. Those who need ideas to stimulate their

Blue-tit trick -- conventional learning or morphic resonance? thoughts about the concept of Christian stewardship will be rewarded.

I disagree with Sheldrake's restatement of Gaia as a purposeful regulation of the material conditions of the Earth by the organisms; but he makes clear that this is his, not my, definition of Gaia. I wish that my opponents from the school of fundamentalist biology were as scrupulous. To Sheldrake, a biologist, the terms animate, alive and life imply purpose. To me, and to many engineers I suspect, the term alive also includes the concept of a system switched on and working, something very different from the same system switched off. Gaia is alive in this sense but in no way has foresight or purpose.

I enjoyed the book. Morphic fields and morphic resonance are fanciful ideas, even for a nonconformist like me, but not distasteful when taken with a pinch of salt.

James E. Lovelock, Coombe Mill, St Giles on the Heath, Launceston PL15 9RY, UK 